Ze'ev Shenkman MD, * Igor Krichevski $\mathrm{MD}, *$ Orly N. Elpeleg MD, ${ }^{\dagger}$ Adina Joseph MD, Avishag Kadari $\mathrm{MD}^{*}$

\section{Anaesthetic management of a patient with Leigh's syndrome}

Purpose: Leigh's syndrome, a progressive neurodegenerative disorder of infancy and childhood, is dinically characterized mainly by developmental delay, nervous system dysfunction and respiratory abnormalities such as aspiration, wheezing, breathing difficulties, gasping, hypoventilation and apnoea. Acute exacerbation and respiratory failure may follow surgery, general anaesthesia or intercurrent ilinesses. Hyperlactataemia is variably present. Histopathological findings indude necrosis, vascular proliferation, astrocytosis and demyelination of several brain areas. We present a 30-month-old patient with Leigh's syndrome anaesthetized for extracorporeal shockwave lithotripsy, and describe the anaesthetic considerations.

Clinical features: Leigh's syndrome was diagnosed at five months of age based on failure to thrive, lethargy, hypotonicity, choreo-athetosis and lactic acidaemia, with basal ganglia hypodense areas demonstrated by brain computerized tomographic scan. Muscle pyruvate dehydrogenase complex and NADH- coenzyme Q oxidoreductase activity were $25 \%$ and $13 \%$ of control. No preoperative respiratory symptoms or signs were present. Preoperative fasting lasted two hours and gastric aspiration was negative. Anaesthesia was induced with ketamine and midazolam im, and $\mathrm{N}_{2} \mathrm{O}$ in oxygen, and maintained with propofol and $\mathrm{N}_{2} \mathrm{O}$. No volatile anaesthetics were used. Intravenous fluids given were $1 / 2$ normal saline and glucose $5 \%$ administered. Besides laryngospasm during anaesthetic induction, relieved by sublingual succinylcholine injection, the perianaesthetic course was uneventful. The lungs were mechanically ventilated and lithotripsy was performed. No adverse sequelae have occurred, and the patient was discharged one day later. Conclusion: Perioperative management of patients with Leigh's syndrome requires cautious attention to the metabolic, neurological and respiratory aspects of the disease, and appropriate selection of anaesthetic drugs.

Objectif : Le syndrome de Leigh, une maladie infantile neuromusculaire progressive, est caractérisé par un retard du développement, un dysfonctionnement nerveux et par des anomalies respiratoires comme l'aspiration, le wheezing, les difficultés respiratoires, le halètement, I'hypoventilation et l'apnée. Une aggravation aiguë et une défaillance respiratoire peuvent survenir après la chirurgie, l'anesthésie générale ou une maladie concomitante. Le syndrome s'accompagne parfois d'hyperlactatémie. L'histopathologie révele de la nécrose, de la prolifération vasculaire, de l'astrocytose et de la démyélinisation de plusieurs régions du cerveau. Nous présentons le cas d'un enfant de 30 mois souffrant du syndrome de Leigh anesthésié pour une lithotripsie extracorporelle par ondes de choc ainsi qu'un aperçu des considérations anesthésiques.

Éléments cliniques : Un diagnostic de syndrome de Leigh a été porté à l'åge de trois mois devant l'absence de développement, la léthargie, l'hypotonicité, la choréo-athétose et l'acidémie lactique et la démonstration d'une démyelinisation des ganglions de la base par tomographie informatisée. Le complexe pynuate-déshydrogénase et l'activité du coenzyme NADH Q oxydoréductase titraient à $25 \%$ et $30 \%$ du controle. En préopératoire, le patient ne présentait aucun signe symptômes respiratoires. Un jeâne préopératoire de deux heures a été imposé ; l'aspiration gastrique s'est avérée négative. L'anesthésie a été induite avec de la kétamine et du midazolam im et du N2O en oxygène et maintenue avec propofol et $\mathrm{N} 2 \mathrm{O}$ sans agent volatil. Le patient a reçu en liquide intraveineux une solution de $\mathrm{NaCl} 0,45 \%$ et de glucose $5 \%$. À l'exception d'un laryngospasme traité à la succinylcholine sublinguale à l'induction, la période périanesthésique s'est déroulée sans incident. La lithotripsie a été réalisée sous ventilation mécanique. II n'a pas eu de séquelles et le patient a obtenu son congé le lendemain.

Conclusion : La prise en charge périopératoire du syndrome de Leigh exige une attention particulière au profil métabolique, neurologique et respiratoire de la maladie ainsi qu'une sélection pertinente des agents anesthésiques.

From the Department of Anesthesiology and CCM, Hadassah University Hospital and the Hebrew University Hadassah School of Medicine, Jerusalem, Israel, the Metabolic Diseases Unit' and the Pediatric Neurology Unit, „ Shaare Zedek Medical Center and the Hebrew University, Jerusalem, Israel.

Address correspondence to: Ze'ev Shenkman MD, Anesthesia Department/Bader 3, The Children's Hospital, 300 Longwood Avenue, Boston, MA 02115-5737, USA; Phone: 617-355-6225; Fax: 617-355-7887. Accepted for publication June 21, 1997. 


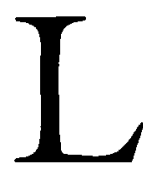

EIGH'S syndrome (subacute necrotizing encephalomyelopathy) is a progressive neurodegenerative disorder of infancy and early childhood, that was first described in 1951 by Denis Leigh. ${ }^{1}$ It is characterized by failure to thrive (FTT), developmental delay, brainstem dysfunction, seizures, peripheral neuropathy, optic atrophy, and altered temperature regulation. ${ }^{2-4}$ Respiratory abnormalities may include breathing difficulties, propensity to aspiration, sobbing, sighing, gasping, suffocating, hyperventilation, "asthma," stridor, gross rhythm irregularity and apnoea. ${ }^{2,3,5}$ With progression of the illness, central hypoventilation and apnoea become more apparent. ${ }^{4}$ Acute exacerbation may follow surgical procedures $^{3}$ or intercurrent illnesses ${ }^{4}$ and respiratory failure has been reported after general anaesthesia. ${ }^{3,5}$ Increased serum lactate and pyruvate concentrations are variably present. ${ }^{2,3}$

Histopathological findings include symmetrical foci of necrosis accompanied by vascular proliferation, astrocytosis and demyelination in the basal ganglia, brainstem and spinal cord..$^{2-4,6}$

Leigh's syndrome has been reported in parients with pyruvate dehydrogenase complex $(\mathrm{PDHc})$ defect and various defects of the mitochondrial respiratory chain..$^{7-11}$ These conditions share in common impaired energy production and lactic acidaemia which possibly play an essential role in the pathogenesis of the syndrome.

Diagnosis is generally based on the combination of the specific clinical abnormalities, a characteristic magnetic resonance imaging (MRI) or computerized tomographic scan (CT) appearance (MRI is much more sensitive than CT scan), and raised serum or cerebrospinal fluid lactate and pyruvate. ${ }^{5,12,13}$ The most constant radiological finding is bilateral radiolucent or hypodense regions in the basal ganglia, most often localized in the putamina. Bilateral symmetrical low density areas have been reported in the thalamus, throughout the midbrain and adjacent to the fourth ventricle, and scattered throughout the brain. These findings are dynamic and may vary with time. ${ }^{12}$

Anaesthesia has rarely been reported in patients with Leigh's syndrome. ${ }^{5,11,14}$ In addition, to the best of our knowledge, urinary calculi have never been associated with this syndrome. In previously reported anaesthetics, thiopentone $e^{5,11,14}$ and volatile agents ${ }^{5}$ were used, although the potential adverse effects of these in Leigh's syndrome have been described. ${ }^{3,11,14}$ Attention to normoventilation, acid-base status, and iv administration of fluids without lactate, ${ }^{3,11}$ as well as the avoidance of elective anaesthesia in patients with respiratory manifestations of Leigh's syndrome ${ }^{5}$ have been recommended.
We describe the anaesthetic course for extracorporeal shockwave lithotripsy (ESWL) in a child with Leigh's syndrome, and review the anaesthetic considerations.

\section{Case report}

A 30-month-old girl of Jewish-Kurdish origin was admitted for lithotripsy of a right ureter calculus, manifested by recurrent vomiting, apathy and right abdominal tenderness. Abdominal ultrasound and intravenous pyelogram disclosed a $7 \times 10 \mathrm{~mm}$ opaque stone in the proximal right ureter causing moderate hydronephrosis. A 24 -hr urine oxalate was $26 \mathrm{mg}$ (normal: 5-40) and a qualitative test for calciumoxalate-phosphor crystals was positive.

Leigh's syndrome was diagnosed at the age of five months based on a clinical picture of FTT, lethargy, muscle hypotonia, choreo-athetosis and absent deep tendon reflexes, lactic acidaemia (arterial blood PH7.35, serum lactate concentration 4.4 and 6.1 $\mathrm{mMol} \cdot \mathrm{L}^{-1}$ in fed and fasting states, respectively; normal $\leq 2.1$ ), and symmetrical hypodense areas in the basal ganglia demonstrated by brain CT. In muscle tissue, the activity of PDHc and NADH-coenzyme $\mathrm{Q}$ oxidoreductase (complex I of the respiratory chain) were reduced to $25 \%$ and $13 \%$ of control, respectively. The activities of citrate synthase, cytochrome $\mathrm{C}$ oxidase and succinate:cytochrome $\mathrm{C}$ oxireductase were within the normal range. Treatment with dichloroacetate (40 mg. $\mathrm{kg}^{-1} \cdot \mathrm{day}^{-1}$ twice a day), riboflavin (50 $\mathrm{mg} \cdot$ day $^{-1}$, once daily) and thiamine $\left(25 \mathrm{mg} \cdot\right.$ day $^{-1}$ once daily) was initiated (and still continued during present admission). Serum lactate had normalized, and a brain MRI performed at the age of 12 mo was normal. At the age of eight months, percutaneous feeding gastrostomy was inserted uneventfully under halothane- $\mathrm{N}_{2} \mathrm{O}$ anaesthesia because of feeding difficulties. The patient's medical history was negative for respiratory symptoms.

On the present admission, weight was $13.3 \mathrm{~kg}$ and height was $82.5 \mathrm{~cm}$ (50th, and < 3rd percentiles, respectively). Psychomotor development was severely retarded. She understood simple words only, and did not talk. The choreo-athetoid movements had disappeared but dystonic posturing was still evident. She could roll over and sit steadily but did not crawl. She could perform only very simple fine motor tasks. Deep tendon reflexes were easily elicited. The rest of the physical examination, including the respiratory system and chest $\mathrm{x}$-ray, were normal. Serum lactate concentration was $1.5 \mathrm{mMol} \cdot \mathrm{L}^{-1}$. Arterial blood gas analysis revealed oxygen saturation of $92 \%, \mathrm{PO}_{2}-65 \mathrm{mmHg}, \mathrm{PCO}_{2}-31 \mathrm{mmHg}, \mathrm{pH}-7.36$ and base excess of $-6 \mathrm{mMol} \cdot \mathrm{L}^{-1}$. 
Preoperative fasting lasted four hours except for water administration through the gastrostomy which continued until two hours before anaesthetic induction. Aspiration of the stomach through the gastrostomy before anaesthetic induction was negative for fluid or solid material. No drugs were given before anaesthetic induction. Intraoperative monitoring included ECG, non-invasive automatic arterial pressure, pulse oximetry, $\mathrm{CO}_{2}$ capnography and oesophageal temperature.

General anaesthesia was induced with $80 \mathrm{mg}$ ketamine, $1 \mathrm{mg}$ midazolam and $0.2 \mathrm{mg}$ atropine $i \mathrm{~m}$, and inhalation of $\mathrm{N}_{2} \mathrm{O} 70 \%$ in oxygen by face mask. While peripheral venous cannulation was attempted, laryngospasm with desaturation occurred. Since it did not respond to the administration of continuous positive airway pressure (CPAP) with oxygen $100 \%$ and, to achieve prompt muscle relaxation, $30 \mathrm{mg}$ succinylcholine was injected sublingually. Successful mask ventilation was quickly resumed and haemoglobin saturation rapidly increased from $39 \%$ to $98 \%$. Cardiac arrhythmias were not observed on the ECG monitor. After cannulation of a peripheral vein and deepening of anaesthesia with propofol (total dose $50 \mathrm{mg}$ ) and $20 \mathrm{mg}$ lidocaine $i v$, orotracheal intubation was easily accomplished using a $4.5 \mathrm{~mm}$ ID Portex tube and the lungs were mechanically ventilated. Anaesthesia was maintained with $\mathrm{N}_{2} \mathrm{O} 70 \%$ in oxygen and propofol at a rate of $125-175 \mu \mathrm{g} \cdot \mathrm{kg}^{-1} \cdot \mathrm{min}^{-1}$. The patient was transferred to the hydraulic chair of the Lithotriptor (HM3 Dornier, Munchen, Germany) and immersed in a warm water bath where lithotripsy was performed. The treatment was completed within $40 \mathrm{~min}$, during which the patient received $300 \mathrm{ml}$ half normal saline in dextrose $5 \%$ iv. Oxygenation, ventilation, haemodynamic and metabolic status and temperature remained normal.

The anaesthetic maintenance and recovery, and the postoperative course were uneventful. Plain abdominal $x$-ray performed in the next day demonstrated few stone fragments along the ureter, and the patient was discharged home. Fourteen days later, no urinary calculi were seen, and the size of the renal shadow had decreased.

\section{Discussion}

The anaesthetic management for lithotripsy of a 30month-old patient with Leigh's syndrome is described. The syndrome was previously diagnosed based on physical and developmental delay, neurological manifestations and lactic acidaemia, with basal ganglia hypodense areas demonstrated by brain CT. Treatment with dichloroacetate, riboflavin and thiamine was initiated and it seemed that the metabolic status of the patient was optimized since serum lactic acid concentration and $\mathrm{pH}$ were normalized. Anaesthesia was induced with ketamine and midazolam $i m$, and $\mathrm{N}_{2} \mathrm{O}$ in oxygen, and maintained with propofol and $\mathrm{N}_{2} \mathrm{O} / \mathrm{O}_{2}$. No volatile anaesthetic was used. Laryngospasm during anaesthetic induction was relieved by sublingual succinylcholine injection. The lungs were mechanically ventilated to achieve normoventilation. A peripheral artery was not cannulated since the procedure was not a major operation, and without fluid shifts. Intravenous fluids consisted of $1 / 2$ normal saline in glucose $5 \%$. Plasma lactate concentration and venous blood acid-base status were normal before and during anaesthesia.

The metabolic lesion in Leigh's syndrome is related to deficiency of the $E_{1 \alpha}$ subunit of PDHc, defects of the mitochondrial respiratory chain (complex I, II or IV), and a $\mathrm{T}-\mathrm{G} / \mathrm{C}$ substitution at position 8993 of the mitochondrial tDNA leading to impairment in complex $\mathrm{V}$ activity. ${ }^{7-11}$ These conditions share impaired energy production and lactic acidaemia which possibly play an essential role in the pathogenesis of Leigh's syndrome. In our patient, PDHc and complex I activity was found to be reduced in muscle tissue homogenate. Dichloroacetate treatment was begun since it inhibits the activity of PDHc physiological inhibitor, i.e., PDHc kinase. ${ }^{15,16}$ Thiamine was added since it is overutilized by $\mathrm{PDHc}$ when dichloroacetate is administered. Riboflavin was added since there are few reports describing favourable clinical and/or biochemical response to riboflavin administration. ${ }^{17}$ The exact mechanism of action of riboflavin is unknown, but it may stabilize complex I assembly. ${ }^{17}$ All three drugs are administered orally. The beneficial effects of dichloroacetate appear within six hours ${ }^{15}$ to seven days, ${ }^{16}$ and its plasma half-life after a single po or $i v$ dose is $0.5-2 \mathrm{hr}^{15}$ The effect of dichloroacetate after a single oral dose is surprisingly long-lasting, with individuals requiring one to eight weeks between doses before the original plasma clearance rate is restored. ${ }^{15}$ Dichloroacetate administration has been associated with hyperoxaluria, ${ }^{15}$ and it is possible that it contributed to the appearance of the urinary stone and the qualitative test for calcium-oxalate-phosphor crystals in our patient, although the 24-hr urine oxalate excretion was normal.

Experience in the anaesthetic management of this syndrome patients is limited to a few patients. ${ }^{5,11,14}$ As opposed to previous reports, ${ }^{5,11,14}$ we avoided the use of barbiturates and volatile agents which may adversely affect patients with Leigh's syndrome (see below).

The use of neuromuscular relaxants in Leigh's syndrome patients has never been studied, and it would be advisable to titrate the administration of short acting muscle relaxants according to neuromuscular monitoring. The perioperative administration of opioids and 
$\mathrm{H}_{2}$ receptor blocking agents or antacids, also have not been studied in these patients. Likewise, although myopathy may be associated with malignant hyperthermia, no such association has been described for Leigh's syndrome.

In order to avoid hypovolaemia and hypotension during anaesthetic induction which may exacerbate lactic acidosis, clear fluid administration continued until two hours before the procedure. Since physical examination had revealed difficulties in venous catheterization, and since we wanted to avoid the use of volatile anaesthetics, anaesthetic induction was accomplished with im ketamine and midazolam, and inhalation of $\mathrm{N}_{2} \mathrm{O}$ in oxygen by a face mask. Succinylcholine was administered due to laryngospasm that was unresponsive to CPAP with oxygen $100 \%$, and resulted in a quick-onset muscle relaxation. We injected it sublingually rather than im since it was estimated that the high vascularity of the floor of the mouth would allow rapid absorption of the drug, as opposed to the potentially decreased muscle blood flow in a myopathic patient. However, the prevention of hypoxaemia and hypercapnia, which are known causes of metabolic and respiratory acidosis, should be weighed against avoiding volatile anaesthetics in patients with Leigh's syndrome. It might have been safer to induce anaesthesia with inhalational agents and maintain it with intravenous anaesthetics, with the hope that the brief exposure to volatile anaesthetics would not lead to metabolic deterioration. Anaesthesia was maintained with $\mathrm{N}_{2} \mathrm{O} / \mathrm{O}_{2}$ and propofol for rapid recovery, as well as to avoid the use of volatile anaesthetics.

The major anaesthetic problems related to Leigh's syndrome are derived from the associated respiratory abnormalities, the tendency to metabolic acidosis and the possible adverse metabolic effects of some of the commonly used anaesthetic agents.

Preparation for anaesthesia and surgery should include attention to the presence of respiratory symptoms or signs, swallowing difficulties and propensity to aspiration, since the presence of the above respiratory abnormalities, which may be intermittent, not only constitutes a clue for diagnosis, but also often signals the beginning of the final deterioration. ${ }^{5}$ This may also predict the development of post-anaesthetic respiratory failure. $^{5}$ It has been recommended, therefore, to avoid elective anaesthesia in patients with respiratory manifestations of Leigh's syndrome. ${ }^{5}$ It is suggested that, if operation is unavoidable in patients with respiratory manifestations, postoperative intensive respiratory care is needed. Since no clinical or laboratory respiratory abnormalities were present in our patient, it was decided that her mild hypoxaemia would not contraindicate anaesthesia for the relatively urgent lithotripsy.
Inasmuch as pyruvate cannot enter the citric acid cycle in patients with a defect of pyruvate dehydrogenase complex, lactic and pyruvic acidosis may develop. ${ }^{3,11,12}$ Therefore, blood lactate concentrations and $\mathrm{pH}$ should be monitored. Since it is not clear if lactate plays a role in the development of the syndrome or if hyperlactataemia is just one of its manifestations and, since the liver does not completely metabolize the excess of endogenous lactate, lactate-containing fluids (e.g., lactated Ringer) are better avoided. ${ }^{3,14}$ In addition, the acidic $\mathrm{pH}$ of lactated Ringer ( $\mathrm{pH}-6.5$ ) may also preclude the use of this solution in Leigh's syndrome patients. Mechanical ventilation may be desirable during anaesthesia in Leigh's syndrome patients, to prevent respiratory acidosis and to compensate for the metabolic acidosis. If metabolic acidosis is accentuated, iv sodium bicarbonate administration may be considered. However, hyperventilation should also be avoided, since hypocapnia might inhibit pyruvate carboxylase and worsen lactic acidaemia. ${ }^{3,11,14}$ Moreover, respiratory alkalosis can lead to the release of lactate from muscle tissue, aggravating the lactic acidosis. ${ }^{18-20}$

Although experience in the anaesthetic management of patients with Leigh's syndrome is too limited to permit specific recommendations for drug selection, ${ }^{3}$ selection of anaesthetic agents should take into consideration the interference of barbiturates and volatile agents with mitochondrial respiration, $, 111,21,22$ and the ability of halothane to inhibit gluconeogenesis, leading to hyperlactataemia and exacerbating lactic acidosis. ${ }^{14,21}$ No such an association is described for propofol.

In summary, the perioperative management of a patient with Leigh's syndrome needs a careful attention to the metabolic, neurologic and respiratory derangements that occur with the disease. Meticulous attention to appropriate selection of anaesthetic agents and fluids, normoventilation and prevention of acidosis, and avoidance of elective anaesthetics in a patient with respiratory manifestations of the disease, are important issues in the perianaesthetic management of these patients.

\section{References}

1 Leigh D. Subacute necrotizing encephalomyelopathy in an infant. J Neurol Neurosurg Psychiatry 1951; 14: 216-21.

2 Haslam RHA. Encephalopathies. In: Nelson WE, Behrman RE, Kliegman RM, Arvin AM (Eds.). Nelson Textbook of Pediatrics, 15th ed. Philadelphia: WB Saunders Company, 1996: 1713-6.

3 Stoelting $R K$, Dierdorf SF. Diseases of the nervous system. In: Stoelting RK, Dierdorf SF (Eds.). Anesthesia 
and Co-Existing Disease, 3rd ed. New York: Churchill Livingstone Inc., 1993: 181-250.

4 Korson $M$, Irons $M$, Levy $H$, Morton $D H$. Mitochondrial diseases: disorders of pyruvate metabolism and oxidative phosphorylation. In: Avery ME, First LR (Eds.). Pediatric Medicine, 2nd ed. Baltimore: Williams \& Wilkins, 1994: 1032-48.

5 Grattan-Smith PJ, Shield LK, Hopkins IJ, Collins KJ. Acute respiratory failure precipitated by general anesthesia in Leigh's syndrome. J Child Neurol 1990; 5 : 137-41.

6 Montpetit VJA, Andermann F, Carpenter S, Fawcett JS, Zborowska-Sluis D, Giberson HR. Subacute necrotizing encephalomyelopathy. A review and a study of two families. Brain 1971; 94: 1-30.

7 DeVivo DC, Haymond $M W$, Obert KA, Nelson JS, Pagliara $A S$. Defective activation of the pyruvate dehydrogenase complex in subacute necrotizing encephalomyelopathy (Leigh disease). Ann Neurol 1979; 6: 483-94.

8 Willems JL, Monnens LAH, Trijbels JMF, et al: Leigh's encephalomyelopathy in a patient with cytochrome $c$ oxidase deficiency in muscle tissue. Pediatrics 1977;60: 850-7.

9 Van Erven PMM, Gabrëlls FJM, Ruitenbeek W, et al. Subacute necrotizing encephalomyelopathy (Leigh syndrome) associated with disturbed oxidation of pyruvate, malate and 2-oxoglutarate in muscle and liver. Acta Neurol Scand $1985 ; 72: 36-42$.

10 Santorelli $F M$, Shanske S, Macaya $A$, DeVivo DC, DiMauro $S$. The mutation at nt 8993 of mitochondrial DNA is a common cause of Leigh's syndrome. Ann Neurol 1993; 34: 827-34.

11 Ward DS. Anesthesia for a child with Leigh's syndrome. Anesthesiology 1981; 55: 80-1.

12 van Erven PMM, Cillessen JPM, Eekhoff EMW, et al. Leigh syndrome, a mitochondrial encephalo(myo)pathy. A review of the literature. Clin Neurol Neurosurg 1987; 89: 217-30.

13 Brown TCK, Fisk GC. Medical diseases and anaesthesia. In: Brown TCK, Fisk GC (Eds.). Anaesthesia for Children, 2nd ed. London: Blackwell Scientific Publications, 1990: 337-76.

14 Dierdorf SF, McNiece WL. Anaesthesia and pyruvate dehydrogenase deficiency. Can Anaesth Soc J 1983; 30: 413-6.

15 Stacpoole $P W$. The pharmacology of dichloroacetate. Metabolism 1989; 38: 1124-44.

16 De Stefano N, Matthews PM, Ford B, Genge A, Karpati $G$, Arnold $D L$. Short-term dichloroacetate treatment improves indices of cerebral metabolism in patients with mitochondrial disorders. Neurology 1995; 45: 1193-8.

17 Ogle RF, Christodoulou J, Fagan E, et al. Mitochondrial myopathy with $\mathrm{tRNA}{ }^{\mathrm{Leu}(\mathrm{UUR})}$ mutation and complex I deficiency responsive to riboflavin. J Pediatr 1997 ; 130: 138-45.

18 Herzog S, Weisberg S, Blausten DI. Oral surgical management of a patient with glycogen storage disease type I. J Oral Maxillofac Surg 1986; 44: 999-1002.

19 Cox JM. Anesthesia and glycogen-storage disease. Anesthesiology 1968; 29: 1221-5.

20 Casson $H$. Anaesthesia for portocaval bypass in patients with metabolic diseases. Br J Anaesth 1975; 47: 969-75.

21 Biebuyck JF. Anaesthesia and hepatic metabolism: current concepts of carbohydrate homeostasis. Anesthesiology 1973; 39: 188-98.

22 Cohen PJ. Effects of anesthetics on mitochondrial function. Anesthesiology 1973; 39: 153-64. 